This item was submitted to Loughborough's Research Repository by the author.

Items in Figshare are protected by copyright, with all rights reserved, unless otherwise indicated.

\title{
Applying the lens of sensory ethnography to sustainable $\mathrm{HCl}$
}

\section{PLEASE CITE THE PUBLISHED VERSION}

http://dl.acm.org/citation.cfm?id=2494261

\section{PUBLISHER}

(c) ACM

\section{VERSION}

AM (Accepted Manuscript)

\section{LICENCE}

CC BY-NC-ND 4.0

\section{REPOSITORY RECORD}

Pink, Sarah, Kerstin Leder Mackley, Val Mitchell, Marcus Hanratty, M. Carolina Escobar-Tello, T.A. Bhamra, and Roxana Morosanu. 2019. "Applying the Lens of Sensory Ethnography to Sustainable HCl". figshare. https://hdl.handle.net/2134/13175. 
This item was submitted to Loughborough's Institutional Repository (https://dspace.lboro.ac.uk/) by the author and is made available under the following Creative Commons Licence conditions.

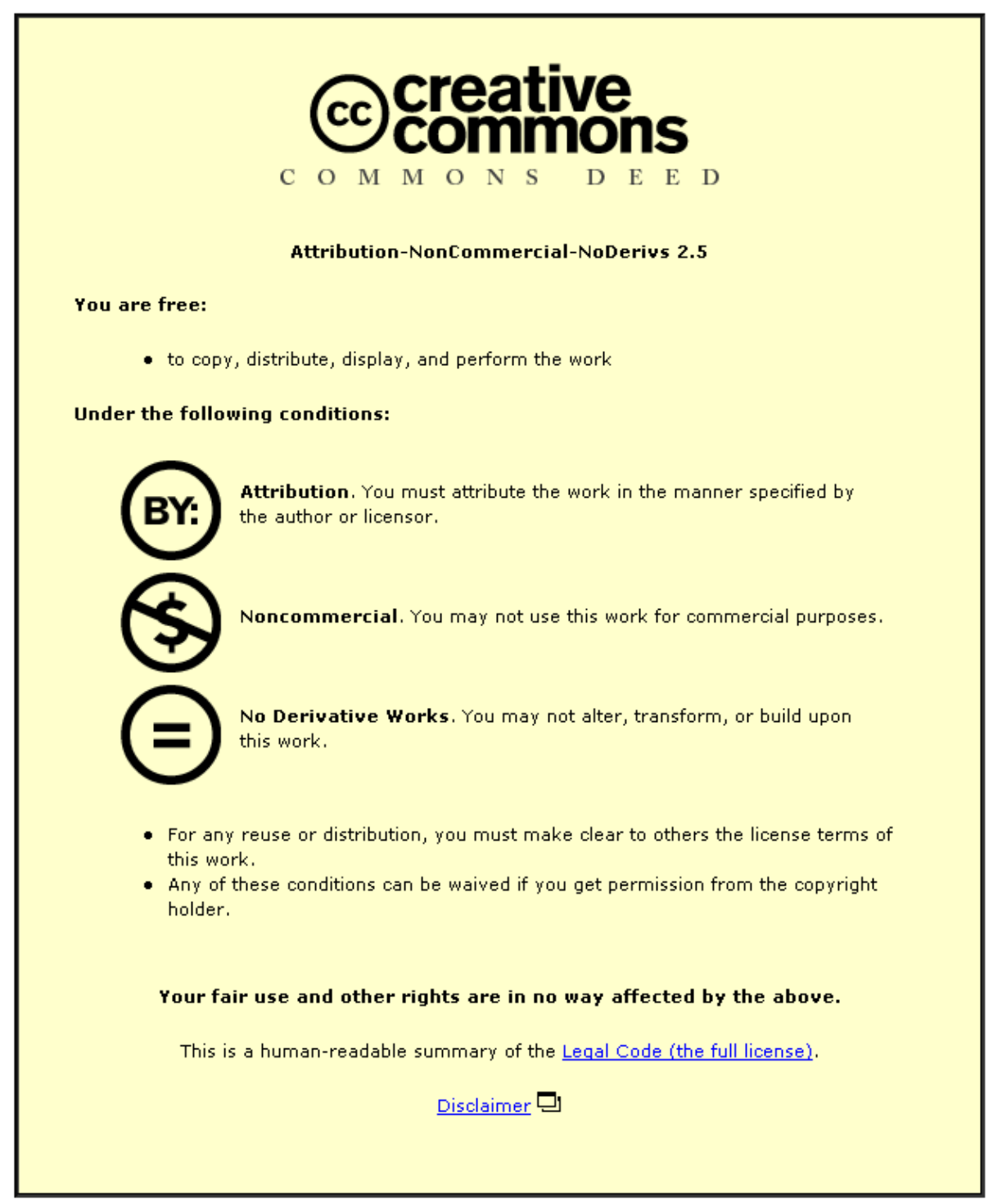

For the full text of this licence, please go to: http://creativecommons.org/licenses/by-nc-nd/2.5/ 


\title{
Applying the Lens of Sensory Ethnography to Sustainable HCI
}

Sarah Pink (RMIT University and Loughborough University), Kerstin Leder Mackley, Val Mitchell, Marcus Hanratty, Carolina Escobar-Tello, Tracy Bhamra, and Roxana Morosanu (Loughborough University)

\begin{abstract}
Sociological appropriations of practice theory as applied to sustainable design have successfully problematized overly simplistic and individualistic models of consumer choice and behavior change. By taking everyday practices as the principal units of analysis, they move towards acknowledging the socially and materially structured nature of human activity. However, to inform sustainable HCI we also need to understand how practices are part of wider experiential environments and flows of practical activity. In this article, we develop an approach rooted in phenomenological anthropology and sensory ethnography. This approach builds on theories of place, perception and movement and enables us to situate practices, and understand practical activity, as emplaced within complex and shifting ecologies of things. Drawing on an interdisciplinary study of domestic energy consumption and digital media use, we discuss ethnographic and design practice examples. We demonstrate how this theoretical and methodological framework can be aligned with the 3rd paradigm of HCI.
\end{abstract}

Key Words: Sensory ethnography, practice theory, third paradigm HCI, energy use, digital media, behavior change, sustainability, design

\section{INTRODUCTION}

Within the third paradigm (Harrison et al. 2007; 2011), also termed third-wave HCI (Bødker 2006; Sengers et al. 2009), designing is considered as a situated and constructive activity of meaning-making and meaning construction (Ylirisku et al. 2009). In line with this trend, an empirical and theoretical focus on practices has begun to emerge within sustainable HCI to comprehend the socio-cultural contexts for and in which designs are created and situated (e.g. Pierce et al. 2010). In this article, we develop this focus on practice by examining how attempts to enable sustainability through HCI design (Mankoff et al. 2007) can be enriched through the types of insights that emerge when we seek to situate practices as part of wider ecologies of place and understand domestic practitioners as individuals whose practice emerges through these ecologies. We suggest that an approach built on theories of place, perception and movement, rooted in phenomenological anthropology (as developed by Ingold 2000, 2011), offers a way to appreciate the merits of an analytical focus on practical activity while moderating the analytical priority given to practices when sociological interpretations of practice theory are applied within design. We introduce this perspective through the example of the UK-based LEEDR project (Low Effort Energy Demand Reduction, 2010-2014). 
LEEDR is an interdisciplinary project which brings together engineers, computer scientists, social anthropologists and designers to develop new understandings of how and why people use energy and digital media in their homes and to test the opportunities afforded by HCI to support more sustainable living. In this article, we draw on findings from the first stage of the sensory ethnography and design strands of LEEDR. Specifically, we develop an extended example based on one of the participating households, both to demonstrate how our approach is applied, and to highlight how our findings can be seen and played out through a concrete example of how digital media practices are actually implicated in wider ecologies of home and in relation to other domestic energy consuming practices. We then connect the sensory ethnography approach and our findings to sustainable HCI in two ways. First, we outline how the sensoryethnographic perspective contributes to the production of a sustainable HCI approach in LEEDR by relating it to three core constructs of the $3^{\text {rd }}$ Paradigm: Place, Experience and Knowing. Second, we show how the ethnographic findings have informed both the creation of design concepts for digital energy saving interventions and the ways we seek to situate digital interventions in everyday life. Such an approach, we propose, offers us an opportunity to research and locate practical activity more firmly within the ways that we conceptualize design interventions.

\section{SOCIAL PRACTICES AND SENSORY ETHNOGRAPHY}

\subsection{Practice theory and design research: possibilities and limitations}

In existing literature, connections between social science and design research have developed to mirror the competing paradigms of psychological theories of behavior change, and sociological renderings of practice theory. While there is no single agreement upon what practices consist of, 'A central core ... of practice theorists conceives of practices as embodied, materially mediated arrays of human activity centrally organized around practical understanding' (Schatzki 2001, p. 2). As Shove et al. write, for practice theorists, 'practices are the fundamental unit of social existence: "both social order and individuality ... result from practices" (Schatzki 1996)', and 'Rather than existing in mental qualities, in discourse or interaction, the social exists in practice' (Shove et al 2007, p. 12). As such a practice approach privileges practices as the central unit of analysis and route to empirical knowledge about otherwise 'messy' (Law 2002) social, material and 'invisible' realities.

Therefore, following Warde's (2005) suggestion that we understand consumption as happening as part of practices, domestic energy consumption becomes accessible empirically and analytically through the study of practices such as laundry, showering (Shove 2003; Gram-Hanssen 2007) or media uses. Interpreted sociologically, practice theory has enabled a critical departure from notions of the individual rational actor that underpin some understandings of behavior change. In the context of energy studies a good example is Strengers' (2011, p. 320) critical observation that evaluations of energy consumption feedback programs are 'based on the same fundamental assumptions that inform their development; namely that when provided with the "right" information about 
the costs and benefits of consumption, individuals will make rational and autonomous choices that result in more efficient resource use'. As Strengers points out, such assumptions neither account for how 'householders actually use consumption feedback in their everyday lives', nor attend to existing sociological research which has demonstrated 'the complex ways in which people actually consume energy and water - which do not often respond to theories of rational action or consumer choice' (Strengers 2011, p. 320). Indeed, sustainable design is increasingly engaging with practice theory to understand complex situated behaviors (e.g. Kuijer and de Jong 2012), and the practice approach has been recognized in a recent report (Chatterton 2011) published by the UK Department of Energy and Climate Change (DECC), as one of four key approaches to understanding 'Energy Behaviour'.

Yet, as practice theorists themselves recognize, like any other theory, one of practice provides an analytical prism onto social, material and sensory realities, but not a complete understanding of them (Reckwitz 2002, p. 257ff; Barnes 2001, p. 18). Moreover, in other fields of scholarship that are, like HCI studies, concerned with media in everyday life, the turn to practice theory is debated and contested. For instance, while the media scholar Nick Couldry (2010) advocates a practice focus, media anthropology scholars are skeptical, criticizing practice theory for its tendency towards abstraction and generalization (Peterson 2010), for its lack of attention to what people actually do and feel, and for its failure to 'stress agency and articulation' (Hobart 2010, p. 63) and 'address the social context in which people engage with, use and argue over or ignore the media' (ibid., p. 69). Therefore while a sociological approach to practice makes an important critical contribution in HCI design research, there is more work to be done in terms of explaining how an understanding of practices can accommodate other contextual and individual elements. One way to advance such an explanation would be from a practice-centric perspective; that is, to interrogate the role of practices in the constitution of context and individual variations. Another is to call on an existing theoretical work that already explains what might be thought of as 'context' in a dynamic and open way. It is the latter route that we pursue, because, as we argue in the next section, such an approach can also account for and situate practices. In the next section we examine how an anthropological approach might enable this.

\subsection{Theoretical underpinnings: putting practice in place}

The anthropologist Tim Ingold characterizes anthropology as not simply a descriptive practice, but rather 'an inquisitive mode of inhabiting the world...a practice of observation grounded in participatory dialogue.... p practice of correspondence' (2008, p. 88). Rooted in reflexive forms of ethnographic practice, an anthropological approach can bring to design research detailed first person encounters with research participants in their environments. It moreover offers a theoretical understanding that encompasses both how people and things are constituted and shaped by these environments and how ethnographic knowledge emerges from our encounters with them. 
The first analytical prism we engage understands the domestic environments we work in through a theory of place. Ingold defines place as a 'meshwork' or 'entanglement' of the lines of things in movement (2007; 2008). Like the geographer Massey (2005), he rejects the idea that places are fixed in localities, inspiring us to think of places as intensities of things (including people) in movement, constantly shifting and changing in form. Place is for Massey 'open', she refers to it as a 'constellation of processes' (2005, p. 141), and for Ingold 'unbounded' (2008). Both theorists emphasize notions of relationality, encouraging us to think about how things are 'mutually constituted' (Massey 2005, p. 184) through their relatedness to each other within 'ecologies of place'. Such theories of place suggest a notion of situatedness whereby people (including researchers and users), things (including homes, technologies, prototypes) and resources (such as energy and water) are part of such ecologies. Recognizing as such that place is constantly shifting, relational and open therefore invites us to consider the contingencies of place; for us this means comprehending the contingencies of the environments where people move and live their everyday lives, of the precise ways they consume energy and technologies, and of research and how ethnographic knowledge is produced.

The relationship between place and practice can be conceptualized through what Cresswell refers to as a notion of 'practiced place', to understand place as both 'in a constant sense of becoming through practice and practical knowledge', and the 'context' for practice (Cresswell 2002: 26), thus suggesting a mutuality between the two concepts. This conceptualization creates a dynamic relationship between practical activity and the making of place. However, rather than presupposing that we should research place through the prism of pre-identified practices, it enables a more open approach to researching how practical activity is both shaped by and harnessed for the making of place. This understanding informs how we do ethnography in the home. To research how place is made and experienced, we tour research participants' homes with them, on video, inviting them to collaborate with us to show us their homes and the activities they engage in to make their homes 'feel right'. In this research encounter, we do not focus on practices themselves, but rather on the on-goingness of practical activity/practice as it is woven into the template of the home as it is made. Yet, as the ethnographic example below shows, the method also reveals where and when in the spatiality and routines of the home the elements of practical activity that might be clustered and conceptualized as identifiable practices are located. Thus the method enables us to situate the components of practices and to bring them together in ways that will support the analysis of selected practices at a later stage of the LEEDR research process.

Our second analytical entry point is movement which, like place, enables us to identify practices, without privileging them analytically. Where researching through place explores how people 'feel' and make the material and sensory elements of their homes, a focus on movement concentrates on the details of the actions they perform to achieve this and acknowledges the uniqueness of human perception. It follows Ingold's concern with both movement and with 'how people perceive the world around them, and how and why these perceptions 
differ' (Ingold 2011b: 323). This focus evades the problems of a 'rational actor' approach or seeking motivations for 'behavior', because it situates perception and practical activity within the ways we move in and as part of the environment. Therefore, accounting for the 'indissoluble relations that exist between minds, bodies, and environment' (Marchand 2010, p. S2), we might situate movement and perception as happening as part of this configuration. Thus we seek to account for how, following Marchand, 'as sentient beings, we are engaged in a changing array of environmental factors at any given moment, all of which impact on the thoughts we think and the actions we produce' (Marchand 2010, p. S2) and, following Ingold, how 'knowledge is grown along the myriad paths we take as we make our ways through the world in the course of everyday activities, rather than assembled from information obtained from numerous fixed locations' (Ingold 2010, p. S121). Thus to understand how and why people consume energy in their homes we ask how people live, move and know in these environments: what and how they experience, at this interface between mind, body and environment as they navigate, go through, participate in and contribute to the making of the place that is home.

To achieve this ethnographically we ask participants to collaborate with us by re-tracing familiar routes through their homes, and in doing so to discuss, reflect on and/or re-enact the actions that they engage in as they move through. On the one hand, the movements, routine actions, and innovations identified through these methods can be seen as dispersed sets of activities that might be clustered into practices - such as the typically dispersed practices of doing the laundry (Pink 2012) or using digital media (Christensen and Røpke 2010). However, the 'things', 'actions' and more that constitute practices - the 'arrays of human activity centrally organized around practical understanding' (Schatzki 2001, p. 2) - are not only parts of practices. Therefore in addition to interpreting these actions as constituting practices we seek to understand what else they might also usefully be considered part of if clustered differently.

\subsection{A sensory ethnography approach}

Since the earliest days of ubiquitous computing in the early 1990s (Weiser, et al. 1999), ethnographic accounts of work and domestic life have influenced HCI design. However, ethnography within HCI is often regarded as 'a toolbox of methods [for extracting data] divorced from a larger set of theoretical and methodological concerns that give it form and rigour' (Dourish and Bell 2011, p. 64), or loosely used to describe in-situ user research through which user requirements for a product or system or more generic 'implications for design' are generated. This reduces ethnography to a method of data collection and misses its potential to produce deeper theoretical insights about the role played by technology in social and cultural worlds (Dourish and Bell 2011; Dourish 2006; Räsänen and Nyce 2006). Existing anthropological ethnography in contrast has shown us how media are indeed implicated in the making of everyday sensory environments. For example, Tacchi's work demonstrates how radio helps create the 'texture' of home (Tacchi 1998) and Pink has likewise shown how radio and music are part of the making of the 'sensory home' (Pink 2004). 
In bringing together research for design with a sensory ethnography approach, we seek to enrich design research practice in two ways: by introducing a coherent theoretical and methodological underpinning that enables us to both attend to the status of the knowledge that ethnography can offer (and thus have a deeper appreciation of its value for design); and by developing an analysis that attends to the experiential, affective, material and social elements of the persons and environments we are designing for. Existing applications of ethnography within design research in domestic settings have advanced practice in this area (e.g. O’Brien et al. 1999 and Swan et al. 2008). However, our engagement with anthropology differs from its existing appropriations within HCI and is more aligned with the sub-discipline of design anthropology (Gunn 2008; Clarke 2011). It also differs from existing approaches to ethnography, including a 'classic' approach that calls for a return to holism (Anderson et al 2007), ethnomethodology (Crabtree 2003) and grounded theory, which seek to build theory from the data, and observational approaches which do not engage in collaborative and participatory tasks with research participants. In line with Dourish and Bell (2011) and Pink (2012), we maintain a consistent theoretical approach to understanding both the processes through which ethnographic knowledge is produced, and the realities that ethnographic research reveals. The sensory ethnography methodology aspires to this by understanding ethnographic practice itself and the realities that are researched through the same theory of place, movement and perception (Pink 2009). In doing so it explores the sensory embodied experience and ways of knowing of both the researcher and research participants as they collaborate to bring these into focus.

\section{FIELDWORK}

\subsection{Method and analysis}

LEEDR involves twenty family households in an English Midlands town and surrounding area. The age of participating children ranges from pre-school to secondary school age, with three households including young adults still living at home. Although the demands of participating in a three-year project were likely to encourage contributions from people already interested in questions of energy use and sustainability, the sample was selected to provide a mix of varyingly environmentally conscious families. Some families’ existing concerns with questions of sustainability were reflected in their everyday choices of transport, food, and waste management. Many had already taken first steps towards reducing their energy bills, for instance by investing in energy-saving light bulbs or cavity wall insulation. At the same time, the sample includes self-confessed 'energy wasters' and 'gadget fiends' (in their words), people who were open about high energy bills and a lack of reflection on their everyday energy consumption.

A first stage of the project involved a number of research activities which were designed to gain an initial understanding of the family homes, both from a technical and social perspective. The design research began by spending an evening with the whole family focused around the sharing of a take-away meal attended by members of both social science and design teams. This 'Getting to 
Know You' study included a semi-structured conversation about the family's home and history, their understandings of energy and sustainability within the home and the wider context, as well as their hopes and worries for the future. An interactive participative research activity encouraged participants to map on a floor plan of their house their everyday routines and movement though their home (for both typical winter and weekend days) (Figure 1). Before the installation of energy monitoring equipment, the next visit was a home video tour that formed the basis for the sensory ethnographic research discussed in this paper. The subsequent energy monitoring is used to provide a quantitative measurement of the environmental impact associated with given practices, which in turn directs design investigation towards those practices deemed to be high consumers of energy.

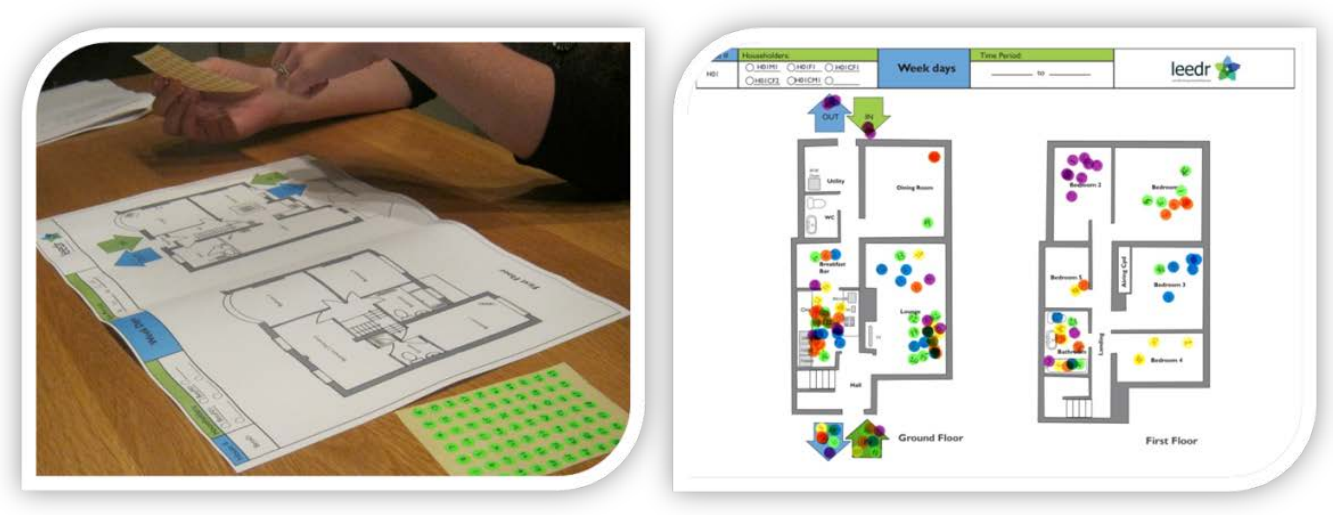

Figure. 1. Participative task mapping family routines. (c) LEEDR, Loughborough University, 2011.

Following the same principles that we use to understand knowing in everyday life, our ethnographic ways of knowing emerge from the researcher's participation in places of which she/he was both a constituent and co-constitutor. Therefore if we understand place as constituted through movement, we can see how participants and ethnographers make knowledge and places together as they tour the home. This enables the sensory ethnographer to focus on how the place(s) she/he seeks to understand are constituted both in the experience of participants and in the ethnographic descriptions she or he ultimately creates.

During the video tours we focused on how participants create, maintain, and experience the 'sensory aesthetic' of their home (Pink 2004). One or more family members guided the ethnographer around their house with the central task of telling and showing us how they make (or seek to make) the home 'feel right'. The tour is both an interview in movement, using the materiality, sensoriality and affective meanings of the home itself as prompts and props, and a performative encounter where participants use their whole bodies to express and show us what it is like to live in and continually renew their homes. We covered interior decoration, hidden structural histories, walked over floor surfaces and considered how all of these were related to activities including cleaning, lighting, heating and airing rooms. We wanted to learn about the sounds, smells, textures and those 
other uncategorized embodied and emplaced feelings of home, and how these were negotiated. While energy and media use inevitably played a role in our tours, we avoided direct energy-related questions, not least to reduce participants' sense of having to position themselves in relation to wider 'green' or other moralities (cf. Chetty et al. 2008, p. 250).

Using video is central to our method since it enables what the anthropological filmmaker David MacDougall calls ‘deep reflexivity’ (2005), in contrast to the after-the-event reflexivity that characterizes the way an interviewer reflects on her or his 'bias' or subjectivity in the research process. 'Deep reflexivity' refers to how the research encounter is inscribed in the recording, with the context of the 'construction of meaning' remaining open to interpretation and review (Pink and Leder Mackley 2012). Therefore in the example discussed below the recordings were used as an aide-memoire of the researcher's experience of the research encounter (with both participants and the sensory environment) and a route to reaccess what participants have shown and told us about verbalized and performed ways of knowing, experiencing and making the environment of their homes.

While the videos record some detail of how people interact with their homes and technologies, analytically we treat them as routes to knowledge about how the sensory home is constituted rather than as forms of audiovisual data (for an example of the latter, see Woodruff et al. 2008). The videos offer a rich evocative record of the collaborative research encounter, of researcher and participant moving through the sensory environment of home.

At the analytical stage exemplified through the example discussed below we focused on the processes through which a sensory aesthetic of home is made, the contingencies surrounding this, the material, invisible and human flows through the home, and the habits, routines and practices that form part of the making of home. In doing so, we suggest how both the ongoingness of practical activity and identifiable practices become part of this sensory environment of home. For the purposes of the HCI focus below, we concentrate particularly on how media practices become interwoven with other everyday practices in the making of a sensory and affective aesthetic of home. To demonstrate this, in the next section we present a detailed discussion which shows how media use, heating and other elements of everyday life intersected in just one household. Our intention in focusing on a single example should not be interpreted as a focus on designing for individual families. Rather we have chosen to describe one family in detail in order to demonstrate what we can learn from a sensory ethnography approach. This particular family moreover stands as a good example of the kinds of ways that other families in our sample used media, and we make reference to these themes in later sections. Our focus on media use in this example has two purposes. On the one hand we show how media are part of the way people make and move around the home, as a way to identify how in a context of ubiquitous media use in the home they might be harnessed for the making of digital design interventions. On the other we are concerned with how media uses come together with other activities aimed at making the home 'feel right', including those related to thermal and sonic comfort. 


\subsection{Making home: the 'Barnes' household}

Our tour of the Barnes family's home was led mainly by Sam Barnes (early 40s) with other members of the family - her husband, John (early 40s), daughter Laura (10) and son Tim (7) - also joining in. The parents describe themselves as already environmentally conscious. Amongst other things they grow their own produce and have a small solar-voltaic roof system. However, there are some aspects of their lives (e.g. digital media and foreign travel) that they would find difficult to do without. During their tour there was a focus on 'comfort', which often referred to the idea of achieving the right temperature. Here, the idea of making the home feel right was also bound up in a process of creating comfort or adjusting one's activities and movements according to the affordances of different localities around the home.

As we stepped from the living room into the kitchen, Sam immediately drew our attention to the cold tiles underfoot: 'This, as you can ... tell probably by your feet, it's cooler, and in the winter it's cold.' The family had considered underfloor heating but it was too expensive at the time. A small fan at floor level underneath the cooker assists to keep the cook's feet warm as and when necessary (Figure 2).
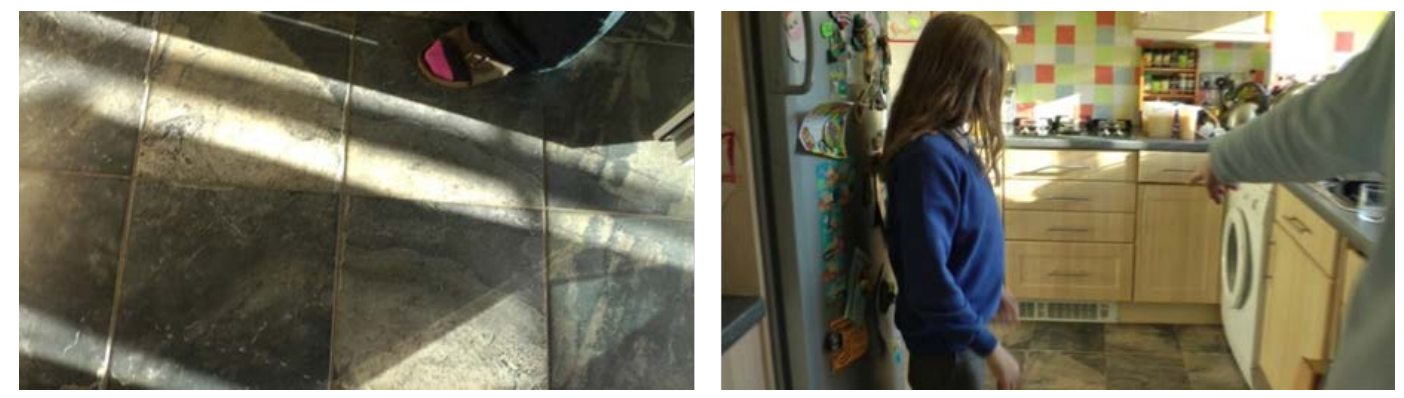

Figure. 2. The cold kitchen floor and floor-level heater (screenshots). (c) LEEDR, Loughborough University, 2011.

The adjacent conservatory can be the warmest, even 'sauna'-like part of the house in the summer, but is the coldest area in winter. A set of additional doors to split the conservatory off from the kitchen area has made some changes to how the kitchen feels in the deepest days of winter. Still, both kitchen and conservatory are generally deemed colder spots during the winter. While lunch is eaten in the conservatory through most of the year, breakfast and dinner move into the dining room area in winter, which extends in a slightly elevated position from the lounge. The lounge is a central place for this family, and time is often spent individually or socially around the television set. Both the TV and the desktop computer in the dining room get switched on when the children come home from school and, as happened during the tour, their use might coincide with that of mobile gaming devices. Already we begin to gain a sense of how the home is made and experienced, and how the localities and areas of the home through which everyday life is lived out, shift seasonally and temporally (see Woodruff et al. 2008 for a related discussion of 'daily and seasonal rhythms'). 
In the living room there is a sense that sitting in front of the TV constitutes a form of down time for different members of the family, as well as family time. To achieve the right temperature or sense of comfort for spending time around the $\mathrm{TV}$, the Barnes family employs a number of strategies. Decoration - such as the carpet, sheepskin rug, fluffy cushions and suede-effect wallpaper - was chosen to add to the warmth and homeliness of the room. The family also had parts of the dining room roof replaced and insulated, which means the rooms do not get as cold as they used to. To keep out any cold air from kitchen or conservatory, both doors to kitchen and corridor are often kept shut and draught excluders placed on the bottom of the doors, as Sam put it 'just to make it doubly snug'.
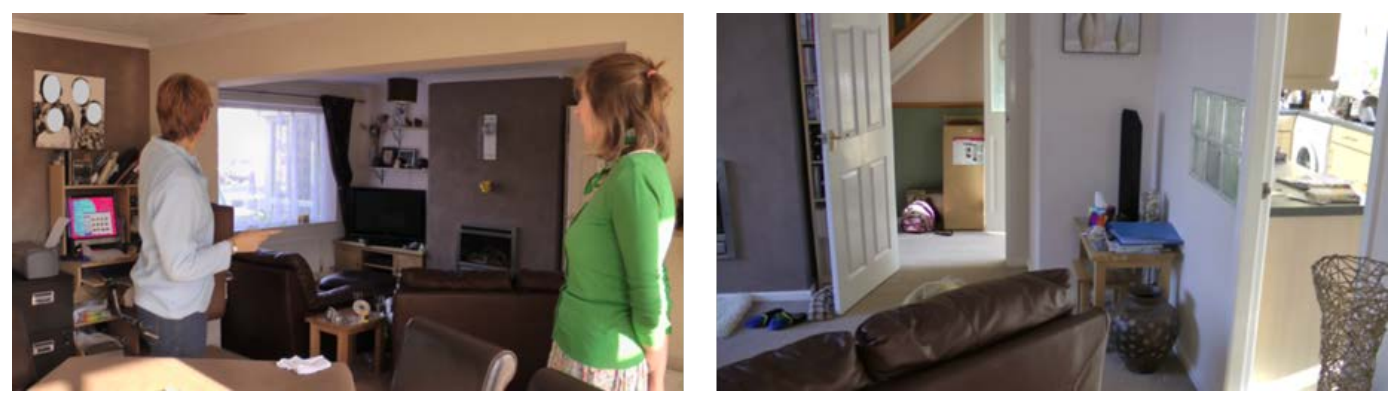

Figure. 3. PC and TV areas with fireplace, adjacent doors with draught excluder (screenshots). (C) LEEDR, Loughborough University, 2011.

In addition to the main living room TV, there are also digital TVs in the master bedroom and kitchen. The latter accompanies other active tasks, such as cooking and ironing in the conservatory. More focused viewing happens in the master bedroom, which is often an alternative family space when the downstairs TV is blocked for use. As Sam explained:

'It does come on if there's a football match that [John] wants to watch on HD [laughs], downstairs, then we get banished, to watch ... upstairs, and I.., we all get in bed. Cos the kids usually sort of had a bath ' $n$... what have you, and they'll get in bed, I'll get in bed with them, and we kind of just watch telly up here. And... [laughing] when the football's finished, we'd go back down. But they quite like that, they quite like coming into our bed and... watch telly.'
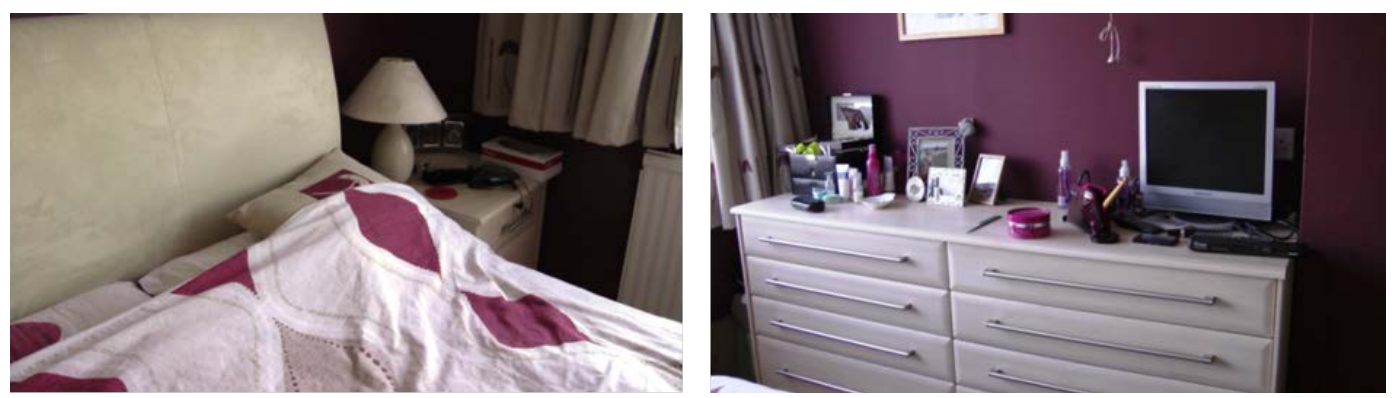
Figure 4. The Barnes’ alternative family television space (screenshot). (C) LEEDR, Loughborough University, 2011.

The TV viewing here is linked to other sensory aims and experiences, such as having a bath on a Saturday night, changing into pyjamas and getting comfortable in bed. As Sam continues, this configuration often happens on a Saturday night because this is the day when television scheduling tends to create most conflict:

'So some of us... end up in here... and what have you, [quickly] even though we've got one [...] in the kitchen, we tend to come up here, cos it's... cosier. The kitchen's there for doing the cooking ' $n$ that sort of thing. [K: 'And you can lay here.'] Yeah. [K: 'I expect you can’t lay in the kitchen’ [laughs]].

This notion of comfort, then, is not directly linked to temperature but to a sense of 'cosiness' and relaxation. Sam also uses lighting to achieve the appropriate sensory environment, for instance by encouraging her son to use the small bedside lamp, rather than the brighter ceiling light, when reading at night. As we found during a subsequent visit with the family, he now also listens to his iPod nano before going to bed, ended by a timer on his clock radio; as Sam put it, 'when that goes off, that's it'. Alongside television and bedtime reading, ending or starting the day with the radio (or iPod docking station) is a habitual part of routines in this home. It serves the purpose of relaxing and signaling bedtime and of allowing the parents downstairs to monitor and control activities upstairs. Listening to the news and weather forecast when waking up in the morning also allows Sam to prepare for the day, for instance by choosing what to wear and whether to take the bike to work.

Here, media are part of sensory environments, where particular materialities, temperatures, socialities and temporalities of home (and of TV programming) come together with media technologies in specific configurations of place. For the Barnes family, there is a certain predictability and routine element to this reflected in the certainty with which everyday life was reported. Yet there are contingencies, in terms of how the use of media is both made possible by, and simultaneously encourages, other practices. This interwoven-ness of the different elements that are needed to create a comfortable environment offers us a route through which to consider how and why people use media in their homes and what they also need to be able to use them. Consequently, we begin to understand everyday uses of media as part of a process that also requires other resources to complete the sensory aesthetic of the environment of home - such as sourcing of the right textures for the sofa and the use of hot water for a bath before bedtime viewing.

We have also seen in this example, in ways that resonate with other families in the LEEDR sample, how using media is part of the way people move around their homes, and engage in practical activity in the home. Media devices went on and off as the family moved between rooms, and started or ended the day. They were also part of other activities which can be understood as part of the process of 
achieving a feeling of 'rightness' at home - doing the ironing and the sensory effects of this, making breakfast, and more. In this sense, and of particular relevance to our discussion of the design intervention below, media are important in two ways. On the one hand they are interwoven with the things people do to make aspects of their homes and lives feel right (ironing, cooking, etc.). On the other hand using media is part of a process of making an environment feel right along with heating, textures and other elements.

\section{BRIDGING THEORY, ETHNOGRAPHY AND DESIGN}

The design team within LEEDR is itself interdisciplinary, including researchers with industrial design, human factors and engineering backgrounds with prior experience of both behavioral and practice-orientated approaches within Sustainable Design (Bhamra et al. 2011; Haines et al. 2012). From the outset, design and social anthropology strands of the project have worked closely together with a desire to move beyond purely uncovering design implications from the ethnographic research towards recognizing the role of ethnography as a tool for building theoretical and empirical understandings for design (Dourish 2006; Räsänen and Nyce 2006).

Sustainability is a complex and 'wicked problem' where problem definition and solution generation are tightly entwined, where different perspectives abound and the problem is never definitively solved (Rittel and Webber 1984; Wolf et al. 2006). Meaning-making rather than a pre-defined design problem will therefore be the initial focus for design activity and central to the overall design process (Ylirisku et al. 2009). Having clear theoretical foundations for making sense of the messiness of reality, we believe, provides a much-needed scaffold for dealing with complexity, identifying and evaluating design opportunities, and for generating principles to guide conceptual design. Therefore the lens of a sensory ethnography approach framed by a theory of place, movement, perception and practice offers us ways to identify the social, material and invisible dimensions of the homes within which we are seeking to reduce energy demand through HCI.

There are clear parallels between the phenomenological sensory ethnography approach and the notion of embodied interaction that is core to $3^{\text {rd }}$ Paradigm HCI (Dourish 2001a). At the heart of both is a commitment to the idea that we encounter the world as a meaningful place within which we act (Harrison and Dourish, 1996): 'It is through our actions in the world - through the ways in which we move through the world, react to it, turn it to our needs, and engage with it to solve problems - that the meaning that the world has for us is revealed' (Dourish 2001b, p. 237).

Within the 3rd paradigm the meaning and nature of interaction is grounded in the specific social and physical context within which the interaction takes place (Harrison et al. 2011). In sustainable HCI, Sengers et al. (2009) have interpreted this as a need to design and evaluate interventions within specific local contexts. Within the approach we have outlined above, place has a more dynamic element than is commonly assumed within HCI, which enables us to go beyond the notion of physical and social context. In the context of the LEEDR project this has 
enabled us to focus on how energy is consumed as part of each home's ecology of place.

From a design perspective this has inspired us to understand more fully how people make place, individually or as a family, both through their coming together in specific areas or localities of home, and by seeing the home as a place in movement. We have seen similar activity around media across our twenty households and have sought to represent this in the example discussed above. For instance, of particular relevance to our discussion in the next section, while the Barnes family made sure they were comfortable watching TV in pyjamas at bed time, another family, the 'Ashtons', snuggled together with duvets on their sofa as if it were an enormous bed to watch TV on weekend evenings. Digital technologies in the form of the TVs, iPads, smart phones and so on, often play a central role as a vehicle for creating these feelings of family and home. These findings raise two questions for the design team concerning the notion of place: First, how, if at all, can families be enabled to create sensorial and meaning-rich temporalities of place that consume less energy? Or, second, can deeper understanding of what is meaningful about technology-mediated comfort making experiences be used to inform the design of alternative positive experiences that allow families to move towards less energy intensive practices (cf. Rogers, 2006; Sengers et al 2009)?

A related theme emerging throughout the sample has focused on movement and flows. In the Barnes family we saw the morning routines of switching TVs and other technologies on and off as people move from room to room. Likewise in other families similar patterns emerged as participants moved through the home either taking mobile technologies with them or using a new technology as they themselves move. Our participants often carried smart phones with them as they went through their homes and picked up iPads on their ways through a room, or as part of a routine. For sustainable HCI in a domestic context, we believe the notions of movement and flow suggest the need to consider situated meaningmaking as not only 'often collaborative' but also often dynamic (cf. Harrison et al 2011). Design practice needs to be able to conceptualize this movement and flow. Design processes that utilize video are well positioned to respond to this challenge (e.g. Ylirisku and Buur 2007), and the sensory ethnography approach enables us to advance this through a strong theoretical framework.

The notion of place that informs the sensory ethnography approach has also led us to consider the impact of the home as a place of transition upon the context and process of design. On one level the home is continually in transition from, for instance, its evening to bedtime to morning time status and, as we have seen, media already figure strongly in these moments. Moreover in our sample we have seen children leaving home and pets arriving, shifting the dynamics of family life and significantly impacting upon energy use. New technologies are also continually appropriated into our participants' homes, leading to reconfigurations of place and new ways of experiencing meaning. We need to design within not outside of this shifting canvas, to develop a 'participative design' (Muller 2003) process within which the design and meaning of our interventions is negotiated with our participant households. 
The sensory ethnography approach like the $3^{\text {rd }}$ paradigm places experience center stage, with the dynamic element of experience being particularly apparent in sensory ethnography. Although more evident in video clips (see Pink and Leder Mackley 2012), the example above highlights how the sensory aesthetic experience of home is shared by both researchers and participants as they move through the home. How people routinely move through their homes and how this impacts upon energy use is a theme that has also been concurrently explored within the design research strand. The participative activity within the Getting to Know You encounters enabled each family to represent their movements through the house on typical mornings and evenings. This together with the video tours is enabling us to construct a picture of the 'peak times' for each family and how they encounter the home, appliances and technology during these times. Thus our design of the user experience for sustainable HCI can seek to respond to this dynamic ebb and flow within family life, for example by recognizing that nonnegotiable practices (Strengers 2011) may be central to a family's morning routine and therefore likely to be an unfruitful focus for design intervention, unless the intervention offers the family convenience as well as energy demand reduction

The design team has particularly valued the creative focus that the approach provides through bringing to the fore the experiential purposes of individuals and families. Sengers et al. (2009) rightly plead for a shift away from moralism within sustainable HCI. Third paradigm HCI, they suggest, draws us towards 'engagement with the environment through enhancement and personal interest rather than guilt' (2009: p. 2). The sensory ethnographic focus on how people create the feel of home and how they use digital media to achieve this draws us to consider how we can create meaningful engagement with sustainability through digital media within the context of everyday life.

As designers and researchers within LEEDR we are seeking to understand how our participants make sense of their everyday reality through their engagements with the world around them. We also want to reflect with them on how they use energy and upon the meaning of sustainability for them as individuals and as families both now and in the future. Recognizing the situated role of the researcher and therefore their role in knowledge construction is core to the sensory ethnography approach and also to the $3^{\text {rd }}$ paradigm. As for sensory ethnography in the context of sustainable HCI, the construction of meaning and knowledge is something that should be negotiated with participants within the context of their everyday lives. Yet, we ultimately want to challenge our participants' understanding and ways of doing things (their everyday practices) through our design interventions. Strengers refers to this as 'realigning responsibilities for consumption' (2011, p. 328). To do this we need to understand more fully how we can enable everyday consumption through design. Through the design process we are thus seeking to introduce interventions which will catalyze changes in the everyday habitual actions of participants. However, by doing this in collaboration with participants we are negotiating the level of disruption to the participants' worlds that they are willing to accept, by taking 
seriously the terms upon which they navigate the contingencies of their everyday lives and make sense in the context of their lives.

The understanding of situated meaning-making provided through the sensory ethnographic approach has provided a means to bring these issues to the fore as we seek to align our design activities with the everyday lives of our participants, as part of the design research process.

\section{DESIGN CASE STUDY - LEEDR}

In the case of LEEDR, the design context - the home - is complex and wide ranging. Sensory ethnography (particularly through 'movement and flow' insights) is allowing designers to begin understanding this 'constantly evolving ecology of place', which is a subjective sensorial, intangible concept that cannot be described, but can be re-enacted as a sensory experience. This approach has allowed the unraveling of the contingencies through which individual families' energy consumption emerges. Moreover it has provided insights into the tacit, changing meanings and motivations that inform individual activity and how these unfold as part of the wider ecology of home. From this the LEEDR designers have been able to extrapolate rich sensory use scenarios for potential interventions, which are informed by our understanding of how contingent activities weave in and out of practices. These scenarios serve to both inform us about where energy is being used while also influencing and inspiring the creation of potential new technologically mediated practices through design.

The benefits of this approach can be seen through the example of the design of an intervention targeting the reduction of temperature settings for space heating. Space heating is the single largest consumer of energy in the participants' homes as well as the entire UK housing stock. It is a part of comfort making practices which themselves are contingent to many other practices in the home. Comfort making often occurs as an accompaniment to other spatially dispersed practices, such as television watching or laundry. The sensory ethnography approach, with its focus on movement and meaning, uncovered a range of ways participants seek to create comfort while describing and enacting ostensibly different practices. It also uncovered the collaborative and dynamic aspects of comfort making, the ways in which it can be a response to the actions of others, such as watching TV upstairs under a blanket because the downstairs TV has been commandeered for the football game. This illuminated the real and continuously experienced ways that participants seek to create comfort in their homes and how this encompasses vastly more than the interface of user and heating programmer. This is crucial in an area where for instance, as Strenger's work illustrated at the beginning of this article (Strengers 2011), there has been a tendency to try to reduce energy consumption through persuasive HCI alone (in her example through consumption feedback via in-home displays). Therefore rather than trying to 'persuade' participants to set a lower temperature on their thermostat in response to persuasive prompts (which would be unlikely to endure beyond the first cold period, or the reaction of the first occupant who senses thermal discomfort), we have based our understanding in the question of how participants already use 
technologies and resources in their homes to produce comfort along with their existing uses of digital media.

Thus the LEEDR design approach has tried to balance the persuasive with the sensory in creating the Acclimatiser intervention, which aims to assist occupants in lowering their set temperatures to $18^{\circ} \mathrm{C}\left(64^{\circ} \mathrm{F}\right)$. Acclimatiser is a smart phone app providing remote control of heating settings while offering people new ways to reduce energy consumption. With participants having arrived at their heat settings over the course of time, often through embodied processes of trial and error, it seemed clear that a straightforward reduction of temperature settings would neither be welcome nor effective. Building on the insight that participants may be responsive to managing a 'baseline' of heating consumption (cf. Pierce et al 2010's work on wider energy feedback systems), we thus developed the concept of automating the temperature reduction over an extended period, at a rate of less than $1^{\circ} \mathrm{C}$ a week. As such, the Acclimatiser seeks to enable a new 'norm' to be established over time, and with sensitivity towards people's situated needs. With the existing programmers and thermostats in the house being replaced by Wi-Fi enabled dumb units, the app becomes the central point of interaction for controlling space heating.
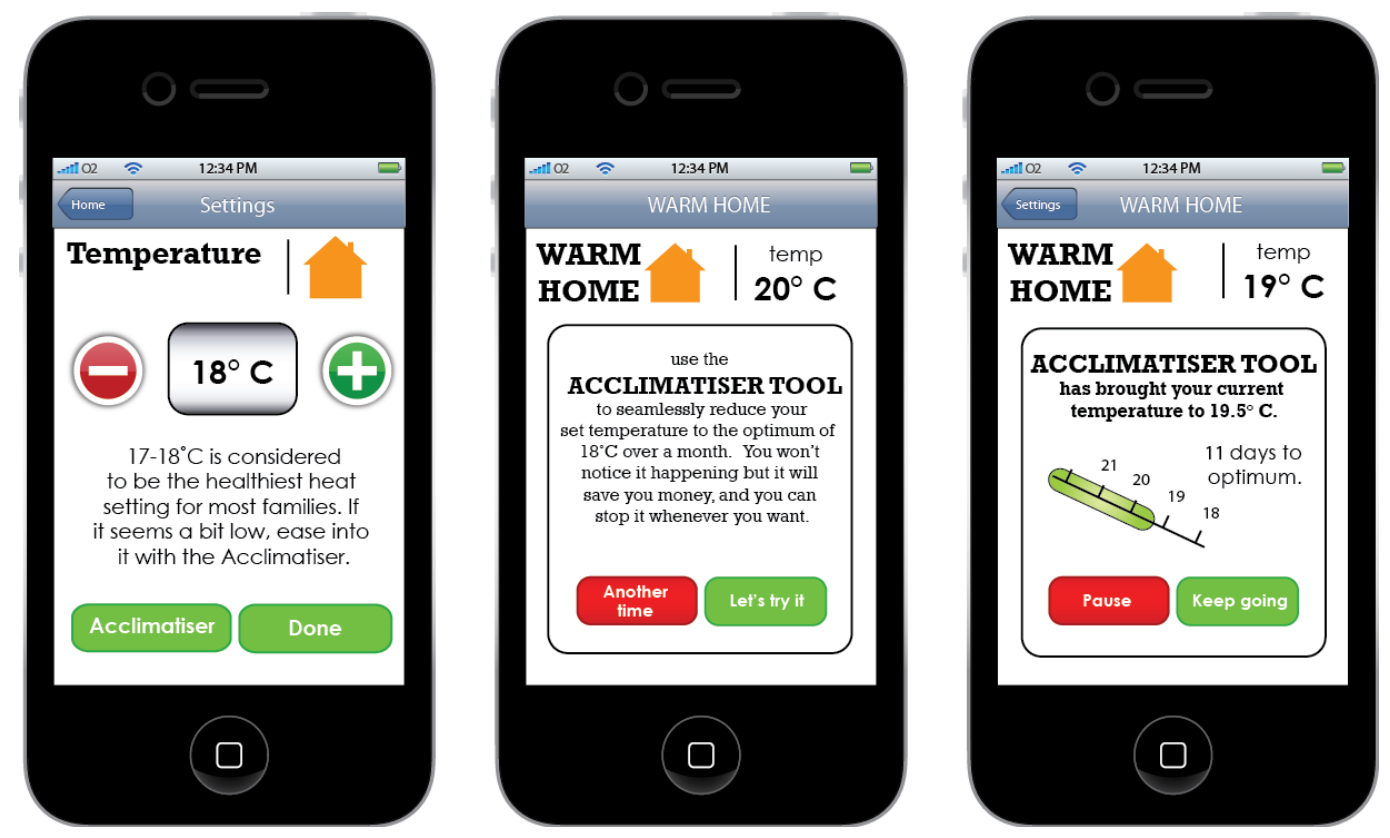

Figure 5. Acclimatiser screen flow. (c) LEEDR, Loughborough University, 2012.

While the main aim of the intervention is to lower and maintain the set temperature, the design recognizes the collaborative and dynamic aspects of this and seeks to utilize the creation of sensory 'domestic moments' (Morosanu 2011) as a bridge to achieving it. To do this it allows the users to have moments of high thermal comfort whenever they desire them, through both digital and physical routes. Digitally, it builds in through interaction design friction to the adjustment of the baseline temperature settings but makes the selection of heat 'boosts' easy; 
these can just be extra half hour periods of heating at the set temperature (i.e. $18^{\circ} \mathrm{C}$ ), or periods of raised temperature (i.e. $21^{\circ} \mathrm{C}$ ). This allows for the normal variance in individual preference to be expressed without the long-term impact related to adjusting static thermostats. As the ethnography has shown, people tend to engage with media as part of their everyday lives in their homes. This was the case, in varying forms and intensities, with all 20 households in our sample. Indeed we noticed an increase in smart phone and tablet usage in the first year of our study, which reflects a wider trend in the UK (Ofcom 2012, p. 4). The intervention therefore offers users a way to direct the temperature of their homes, through interaction with their mobile devices while going about their everyday routines. A digital intervention of this kind is intended to fit both with the notion that people are constantly sensing and seeking to adjust the ways their homes feel (in ways including but also beyond thermal comfort), and that they are often engaging with media in some way as part of everyday practical activity that has the effect of (if not direct conscious intention of) making the home feel 'right' (or at least better). Moreover the physical elements of the design build more directly on the sensory ethnography findings. The intervention includes supplying users with a number of "heat me" bags. These are heat-retaining pouches that can be filled with soft blankets, clothing or other items, and affix to the radiators in the home. These offer a trade-off between the energy saving cooler settings and the anticipated and sensory pleasure of contact with warm cozy blankets and clothes. They enable family members who feel cold easily to have a warm comforting experience that they can easily integrate into their existing practices. The design is influenced by the personal heating practices we found through the sensory ethnography emphasis on the embodied and experiential elements of home. These included a warm bath, pyjamas and blankets, and heating up of clothes on radiators and water heaters as found across a number of households. The intervention gives these practices a new form, which enables people to make their homes feel right through alternative methods. 

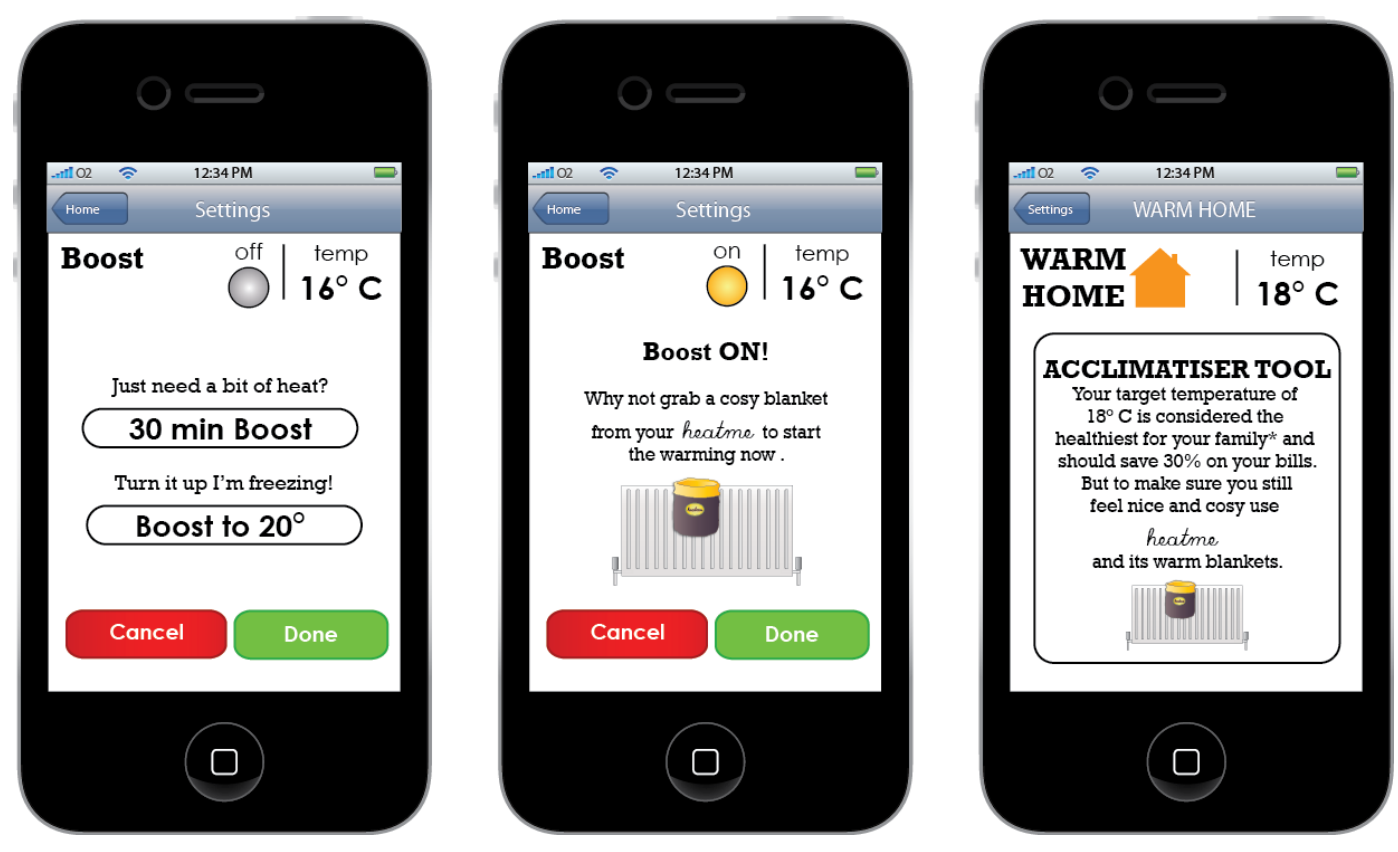

Figure 6. Boost screen flows with Heat Me prompts (C) LEEDR, Loughborough University, 2012.

\section{CONCLUSION}

While acknowledging the value of the third paradigm to sustainable HCI, Dourish calls for this conceptual shift to be accompanied by 'a broadening in the theoretical and conceptual approaches that we use' to research the 'appropriation and meaning of digital media and the cultural and social processes by which it comes to be embedded within everyday life...' (Dourish 2010: p. 8). We argue that the sensory ethnographic approach introduced in this paper is a valuable response to this plea. Through an emphasis on place, movement and perception, sensory ethnography provides a conceptual lens for framing within design that resonates fully with third paradigm HCI. By opening the research agenda to these analytical entry points we have suggested an approach that critiques the assumptions that inform behavior change approaches and the notion of the rational actor. Acknowledging the benefits of a practice theory prism, our approach seeks to identify practices and the elements through which they are constituted, and to comprehend how practices participate in the making of everyday life. However, it goes beyond this by simultaneously enabling us to identify and interrogate practices, and to situate them analytically and empirically as they are produced within and as constitutive of place.

This provides us with both a theoretical and experiential framework for design because it allows us to on the one hand appreciate the meaning and nature of the experiential environments into which we seek to introduce design interventions. On the other it offers us a set of theoretical tools that guide us away from attempts to change 'behavior' and to instead ask how interventions might sit in relation to 
the existing routines, contingencies and innovations that ongoingly make and remake the practices and places of everyday life.

\section{ACKNOWLEDGMENTS}

The interdisciplinary LEEDR project, based at Loughborough University, is jointly funded by the UK Research Councils’ Digital Economy and Energy programmes (grant number EP/I000267/1). For further information about the project, collaborating research groups and industrial partners, please visit www.leedr-project.co.uk. The authors would like to thank all the households who have generously participated in this research.

\section{REFERENCES}

ABOWD, G., DEY, A., BROWN, P., DAVIES, N., SMITH, M. AND

STEGGLES, P. 1999. Towards a better understanding of context and contextawareness. In Handheld and Ubiquitous Computing, Lecture Notes in Computer Science, 1707.

BHAMRA, T., LILLEY, D. AND TANG, T. 2011. Design for sustainable behaviour: using products to change consumer behaviour. The Design Journal, 14, 4, 427-445.

BØDKER, S. 2006. When second wave HCI meets third wave challenges. Proc. 4th Nordic Conference HCI, 1-8.

BULL, M. 2005. No dead air! The iPod and the culture of mobile listening. Leisure Studies. 24, 4, 343-355.

CHATTERTON, T. 2011. An introduction to thinking about 'energy behaviour': a multi model approach. Paper for the Department of Energy and Climate Change, O. Anderson Ed. Department of Energy and Climate Change, UK.

CHETTY, M., TRAN, D., AND GRINTER, R.E. 2008. Getting to green: understanding resource consumption in the home. Ubicomp '08. September 2124. Seoul, Korea.

CLARKE, A. 2011. Design Anthropology: Object Culture in the 21st Century. Springer-Verlag, Heidelberg.

COULDRY, N. 2010. Theorising media as practice. In Theorising Media and Practice, B. Bräuchler and J. Postill, Eds. Berghahn, Oxford, 35-54.

CRABTREE, A. 2003. Designing Collaborative Systems: A Practical Guide to Ethnography. Springer.

DARBY, S. 2010. Smart metering: what potential for householder engagement? Building Research and Information. 38, 5, 442 -57.

DOURISH, P. 2001a. Where The Action Is: The Foundations Of Embodied Interaction. MIT Press, Boston.

DOURISH, P. 2001b. Seeking a foundation for context-aware computing. Human-Computer Interaction, 16, 2-4, 229-241.

DOURISH, P. 2006. Implications for design. CHI 2006, ACM Press, 541-550.

DOURISH, P 2010. HCI and environmental sustainability: the politics of design and the design of politics. In Proc. of Designing Interactive Systems (DIS 2010), August 16-20, Aarhus, Denmark. 
DOURISH, P AND BELL, G. 2011. Divining a Digital Future: Mess And Mythology in Ubiquitous Computing. MIT Press, Boston.

GILL, Z., TIERNEY, M., PEGG, I. AND ALLAN, N. 2010. Low-energy dwellings: the contribution of behaviours to actual performance. Building Research \& Information. 38, 5, 491-508.

GRAM-HANSSEN, K. 2007. Teenage consumption of cleanliness: how to make it sustainable?. Sustainability: Science, Practice \& Policy. 3, 2, 15-23.

GUNN, W. 2008. Learning to ask naïve questions with IT product design students. Arts \& Humanities in Higher Education. 7, 3, 323-336.

HARRISON, S. AND DOURISH, P. 1996. Re-place-ing space: the roles of place and space in collaborative systems. Proceedings of the ACM Conference on Computer-Supported Cooperative Work CSCW'96 (Boston, MA), 67-76. New York: ACM

HARRISON, S., TATAR, D., AND SENGERS, P. 2007. The three paradigms of HCI. In Alt. chi. Proceedings of CHI '07. ACM Press, NY

HARRISON, S., SENGERS, P., AND TATAR, D. 2011. Making epistemological trouble. Interacting with Computers. 23, 385-392

HAINES, V., MITCHELL, V. AND MALLABAND, B. 2012. Merging a practice-orientated approach with an engineering-driven product development: a case study on home improvement, Journal of Design Research, Vol.10, 1/2, 28-49

HOBART, M. 2010. What do we mean by 'media practices'? In Theorising Media and Practice, B. Bräuchler and J. Postill, Eds. Berghahn, Oxford, 55-76.

HOWES, D. 2005. Skinscapes: Embodiment, Culture and Environment. In The Book of Touch, C. Classen, Ed. Berg, Oxford, 27-39.

INGOLD, T. 2007. Lines: A Brief History. Routledge, London.

INGOLD, T. 2008. Anthropology is not ethnography. Proceedings of the British Academy. 154, 69-92.

KUIJER, L AND DE JONG, A. 2011a. Exploring practices of thermal comfort for sustainable design. In Proceedings CHI 2011. ACM, Vancouver, Canada.

KUIJER, L. AND DE JONG, A. 2011b. Practice theory and human-centered design: a sustainable bathing example. Proc. Nordic Design Research Conference, Helsinki.

KUIJER, L. AND DE JONG, A. 2012. Identifying design opportunities for reduced household resource consumption: exploring practices of thermal comfort. Journal of Design Research. 10, 1/2, 67-85.

LAW, J. 2001. After Method: Mess in Social Science Research. Routledge, London.

MANKOFF, J. C., BLEVIS, E., BORNING, A., FRIEDMAN, B.,FUSSELL, S. R., HASBROUCK, J., WOODRUFF, A., AND SENGERS,P. 2007. Environmental sustainability and interaction. Proc CHI EA '07. ACM, 2121212.

MARCHAND, T.H.J. 2010. Making knowledge: explorations of the indissoluble relation between minds, bodies, and environment. Journal of the Royal Anthropological Institute. 16, Issue Supplement, S1-S21.

MASSEY, D. 2005. For Space. Sage, London. 
MOROSANU, R. 2011. Domestic moments of consumption and multisensory experience. Paper presented at the postgraduate group of discussions in material culture and digital anthropology, University College London, October 2011.

MULLER, M. J. 2003. Participatory design: the third space in HCI. In Handbook of HCI. J. Jacko and A. Sears, Eds. Mahway NJ USA, Erbaum.

O’BRIEN, J., RODDEN, T., AND ROUNCEFIELD, M. 1999. At home with technology: an ethnographic study of a set top box trial ACM Trans. Computer Human Interaction. 6, 282 -308.

OFCOM. 2012. Communications Market Report 2012. Available online at http://stakeholders.ofcom.org.uk/binaries/research/cmr/cmr12/CMR_UK_2012 .pdf

PETERSON, M.A. 2010. 'But it is my habit to read the Times': metaculture and practice in the reading of Indian newspapers. In Theorising Media and Practice, B. Bräuchler and J. Postill, Eds. Berghahn, Oxford, 127-146.

PIERCE, J., FAN, C., LOMAS, D., MARCU, G., AND PAULOS, E. 2010. Some considersations on the (in)effectiveness of residential energy feedback systems. CHI 2010, August 16-20, Aarhus, Denmark.

PIERCE, J., SCHIANO, D., AND PAULOS, E. 2010. Home, habits, and energy: examining domestic interactions and energy consumption, CHI 2010, April 10 -15, 2010, Atlanta, Georgia, USA.

PINK, S. (2004) Home Truths: gender, domestic objects and everyday life, Oxford, Berg

PINK, S. 2009. Doing Sensory Ethnography. SAGE. London.

PINK, S. 2011. Drawing with our feet (and trampling the maps): Walking with video as a graphic anthropology. In Redrawing Anthropology, T. INGOLD, Ed. Ashgate, Farnham.

PINK, S. 2012. Situating Everyday Life: Practices and Places, Sage, London.

PINK, S. AND LEDER MACKLEY, K. 2012. Video and a sense of the invisible: Approaching domestic energy consumption through the sensory home. Sociological Research Online. 17, 1, 3, http://www.socresonline.org.uk/17/1/3.html.

RÄSÄNEN, M. AND NYCE, J. 2006. A new role for anthropology?: rewriting 'context' and 'analysis' in HCI research. In Proceedings of the 4th Nordic Conference on Human-Computer Interaction: Changing Roles (NordiCHI '06).

RECKWITZ, A. 2002. Towards a theory of social practices: A development in culturalist theorizing. European Journal of Social Theory. 5, 2, 243-263.

RITTEL, H., \& WEBBER, M. 1984. Planning problems are wicked problems. In Developments in Design Methodology, N. Cross, Ed. John Wiley and Sons, New York, 135-144.

ROGERS, Y. 2006. Moving on from Weiser's vision of calm computing: engaging ubicomp experiences. In Proc. of the Eighth International Conference on Ubiquitous Computing, UbiComp 2006

SCHATZKI, T. 1996. Social Practices: A Wittgensteinian Approach to Human Activity and the Social. Cambridge University Press, Cambridge. 
SCHATZKI, T. 2001. Introduction: practice theory. In The Practice Turn in Contemporary Theory, T. Schatzki, K. Knorr-Cetina and E. von Savigny. Eds. Routledge, London.

SENGERS, P. BOEHNER, K., DAVID, S., AND KAYE, J. 2005. Reflective design. Proceedings of the 4th decennial conference on Critical computing: between sense and sensibility (CC '05), O. W. Bertelsen, N. O. Bouvin, P. G. Krogh, and M. Kyng, Eds. ACM, New York, NY, USA.

SENGERS, P., BOEHNER, K., KNOUF, N. 2009. Sustainable HCI meets third wave HCI: 4 themes. CHI 2009 workshop.

SHOVE, E. 2003. Comfort, Cleanliness and Convenience: The Social Organziation of Normality. Berg, Oxford.

SHOVE E., WATSON M., HAND M. AND INGRAM J. 2007. The Design of Everyday Life. Berg, Oxford.

SHOVE, E. 2010. Beyond the ABC: climate change policy and theories of social change. Environment and Planning A, 42, 6, 1273-1285.

STRENGERS, Y. 2011. Negotiating everyday life: The role of energy and water consumption feedback. Journal of Consumer Culture. 11, 3, 319-338.

SWAN, L., TAYLOR, A. S., AND HARPER, R. 2008. Making place for clutter and other ideas of home. ACM Trans. Comput.-Hum. Interact. 15, 2, Article 9 (July 2008)

TACCHI, J. (1998) 'Radio Texture: Between Self and Others'. In Material Cultures: Why Some Things Matter. D. Miller (ed). Chicago, University of Chicago Press.

WARDE, A. 2005. Consumption and theories of practice. Journal of Consumer Culture. 5, 2, 131-53.

WEISNER, M., GOLD, R. AND BROWN, J.S. 1999. Origins of ubiquitous computing research at PARC in the late 1980s. IBM Systems Journal. 38, 4, 693-696.

WILCOX, S. AND PAWSON, H., Eds. 2010. UK Housing Review 2010/2011 (Compendium: Dwellings, Stock Conditions and Households). http://www.york.ac.uk/res/ukhr/ukhr1011/compendium.htm.

WOLF, T. V., RODE, J. A., SUSSMAN, J., \& AND KELLOGG, W. A. 2006. Dispelling 'design' as the black art of CHI. SIGCHI Conference on Human Factors in Computing Systems. ACM Press, Montréal, Québec, Canada, 521530.

WOODRUFF, A., HASBROUCK, J., AND AUGUSTIN, S. 2008. A bright green perspective on sustainable choices. CHI 2008. April 5-10. Florence, Italy.

YLIRISKU, S., HALTTUNEN,V., NUOJUA, J., AND JUUSTILA, A. 2009. Framing design in the third paradigm. In Proceedings of the 27th International Conference on Human Factors in Computing Systems (CHI '09). ACM, Press, NY, 1131-1140.

YLIRISKU, S., AND BUUR, J. 2007. Designing with Video: Focusing the Usercentered Design Process. Springer, New York. 